inducement to bring out new and improved patterns of instruments; their largest customers are engineers, who, as a rule, have had a very elementary training as surveyors, and are shy of adopting any new instrument or method.

The above remarks apply particularly to land surveying, but are largely true also of hydrographic work. India and Canada have their own Hydrographic Services, but apart from these the Hydrcgraphic Department of the Admiralty has to deal with all the seas and coasts of the Empire, and also with such others as are not dealt with by their own Governments. The task is great, and the resources available are all too small for the work. Even in home waters there is much to be done, if only due to the changes continually taking place in all estuaries. Apart from the shifting of sandbanks, etc., much of the earlier work is not up to the standard of modern requirements.

There is no school where hydrographic surveyors can receive instruction in the principles and theory of their work, and no staff available for studying methods and instruments and bringing them up to date. The hydrographic staff of the Admiralty is recruited from volunteers amongst the younger officers of the executive branch of the Royal Navy who have passed in navigation. They learn their surveying in the surveying ships while work is in progress, and the staff of trained surveyors is at present so limited that it can give little instruction to the beginners. Many officers after serving in a surveying ship for two or more years return to ordinary duties afloat, or specialise in other branches where their knowledge of survey work is of great benefit to them. The remainder are advanced in rank pari passu with the officers of H.M. Fleet. The existence of a school where the theoretical side of the question could be studied would be of great benefit to all.

The principles involved in survey are the same whether applied by land or by sea, and the instruments largely the same. One establishment could usefully study and give instruction in both sides of survey work.

Survey cannot be carried out over large tracts of country without consideration of the science generally known as geodesy, which is really only survey as applied to the earth as a whole. The problems involved in this require not only world-wide data, but also high mathematical skill. Problems interconnected with these are those concerning the tides and terrestrial magnetism, both of great importance to navigation. These, again, are connected with the study of the earth's structure in its wider sense, and so with seismology and geologv. These problems may all be summed up in the word "geophysics."

While a knowledge of geophysics is not necessarv for every survevor, no survey authority can function satisfactorily without it. At the same time few such authorities have the staff available for its proper study. A central institution which could be referred to for information would add greatly to the efficiency of the survey authorities.

The need for a British geodetic institute is admitted by all who are acquainted with the nature and importance of the pressing Imperial and scientific problems which depend on the great surveys. The study of such problems has hitherto been left, in characteristic British fashion, to the initiative of enthusiastic individuals or neglected altogether. Take, for example, the case of the tides-so vital a matter to our sailors. While the late Sir George Darwin still lived it could at least be said that one master-mind was devoted, with some approach to continuity, to the study of the great problems which must be attacked and solved if tidal prediction is to advance beyond its present elementary and scrappy state, but since his lamented death in 1912 the subject has lacked attention.

At the request of the British Association, Prof. $H$. Lamb recently reviewed the whole situation with regard to tides, and in a masterly report indicated the number and importance of the problems awaiting solution. Problems comparable in insistence are connected with the land surveys of our Empire, and a similar review of the general situation, also initiated by the British Association under the stimulus of war, directed attention to the pressing need for some determined effort to attack them. The report opened with this cogent sentence: "There is no institution, association, or department whose business it is to deal with the higher geodesy." Consideration of the report by a special committee, afterwards enlarged, developed in the direction of urging the establishment of a geophysical institute. The need for such an institute has been formally recognised as urgent by the Conjoint Board of Scientific Societies (formed during the war for the study of urgent questions), which appointed a small executive committee (which included the president and secretary of the Royal Society) to press for the immediate establishment of such an institute.

We think it would be difficult to find in any scientific matter greater unanimity amongst all the authorities concerned therein. We trust that sufficient evidence has been given as to both the national importance of the subject and the urgency of the need for action. We await the advent of the vivus benefactor, for, as already indicated, there is a consensus of opinion that such an institution should be established within a university by private benefactions, although assistance might, as a consequence, be forthcoming from national funds. The wide ramifications of survey, geodesy, and geodynamics into mathematical, physical, and engineering sciences call for their study in a university rather than in a departmental atmosphere.

\title{
The Imperial College as a University of Science and Technology. ${ }^{1}$
}

THE real issue is whether a useful and worthy type of university can be erected on the comparatively narrow basis of a limited group of studies. In both primary and secondary education there has been a growing tendency to evolve several distinct types of school. Is it only university cloth that must always be cut to the same pattern? If we consider the enormous complexity of modern civilisation and

1 Synopsis of a paper on "The Proposed University of Science and Technology: Can a Useful and Worthy University be Based on Pure and Applied Science?" read before the Old Students'Association of the Royal College of Science on October I2 by J. W, Williamson. NO. 2660 , VOL. IO6] the degree and extent to which it is based upon science, we must think that, in the region of university education, the time has come for a further differentiation of functions, and that the first step in this development should be the creation of a new type of university based upon pure and applied science, not to supersede, but to supplement, the existing type. The normal type of university, embracing a great number of faculties, would still remain, and ought to be, the predominant and prevalent type.

Science, pure and applied, from its nature, is worthy to rank in educational and cultural values with other 
university studies. It is qualified not less by its extent to form a foundation neither flimsy nor narrow for a university superstructure. During the past halfcentury science has developed not only intensively, but also so extensively as to cover vast fields of knowledge previously undreamt of. The result has been the creation of new sciences, differentiated by their own specialised literature, methods, instruments, practitioners, and societies. The step from a faculty of science in a university to a university of science and technology is in line with the steps that have given us to-day separate professors of inorganic chemistry, organic chemistry, physical chemistry, and metallurgy in place of the one-time professor of chemistry whose ambit included all these subjects.

The Imperial College was styled "Imperial" with deliberate intention from the first. From its charter it is clear that it is set to perform real university work of the highest order in science and technology. There is, moreover, a special need which the Imperial College is peculiarly marked out to fill, but which it cannot do adequately unless it has the status of a university with the power to confer degrees. A large and increasing number of students from the overseas Dominions, after completing their courses in the Dominion universities and technical colleges, go to Europe or America to take up what is essentially post-graduate scientific work, especially in its application to industry. The courses of the Imperial College completely satisfy their needs in this direction, better probably than those of any university in the United Kingdom, but the college in its present status cannot give to such overseas graduates who go through the full post-graduate courses anything more than the college diploma. On the other hand, Zurich and some American and German cities have institutes of technology granting degrees. It has already been pointed out that in the industrial and professional worlds the university degree is recognised as a hallmark and has a commercial value. 'The consequence is that there is a growing tendency among these overseas graduates and scientific students to go to America instead of to England, so that they may have a veritable and recognised technological degree, and not a mere diploma, to show for the work they do; and the Imperial College is thus being starved of a type of student it was deliberately charged at its foundation to receive and train. The loss, and even the danger, to the Empire of such a tendency are obvious.

Such a university of science and technology would be the keystone of the arch of our technical colleges and polytechnics; it would influence and enlarge the conceptions of technical and scientific education throughout the country and the Empire; and it must be of great benefit to the modern industrial research movement by raising the status of technological science, by pouring out a stream of the most highly trained technologists and research workers, and by being the natural head and crown of the national recognition, so long and disastrously delayed, of the vital importance of scientific research, especially in its application to industry.

There is nothing intentionally or inherently injurious to the University of London or to any other university in the proposal to give a university status to the Imperiai College. To propound as a sort of unalterable principle that for Greater London, with a population as large as that of Canada and twice as large as that of Switzerland, there must be one, and only one, university savours rather of an academic dogma than of a balanced educational perspective. The Imperial College and the University of London should be set free to work out each its own future independently of the other. They have divergent aims and interests, and it would be an injurious mistake to force them into an unworkable mésalliance.

\section{Agriculture in Egypt and Cyprus.}

$A^{G}$ GRICULTURAL operations in Egypt are entirely dependent upon the Nile, and all extensions in the direction of taking fresh land into cultivation depend upon the way in which more profitable use can be made of the waters of the Nile and of the fertilising mud that it carries with it. The construction of the Aswan reservoir has rendered it possible to retain much of the flood-water, but even now a large amount is wasted that would aid in the expansion of the cultivated area if it could be conserved. Mr. G. C. Dudgeon (Bull. Imp. Inst., vol. xvii., No. 3) sets forth a statistical estimate of the possible and available water-supply, together with the theoretical annual consumption of water for the chief crops. It is suggested that if certain proposed schemes of reclamation were carried out, the whole water requirements of Egypt would be met by less than 60 per cent. of the mean annual discharge of the Nile.

Under the auspices of the Egyptian Ministry of Agriculture, special attention is being given to the various problems of crop and animal husbandry with the view of improving the agriculture of the country (Agricultural Journal of Egypt, vol. ix., I9I9). The war emphasised the local needs, and revealed deficiencies in many directions, especially in labour, animals, and manures. Motor-tractor ploughing is now advocated, and the adoption of machine-threshing would result in better quality grain and flour, as the present native system introduces a large percentage of mud into the product which cannot be removed by any known mechanical means. As cattle manure is being used more and more as fuel, increased proNo. 2660 , VOL. I06] duction is now dependent chiefly upon the use of chemical fertilisers, and there are possibilities that if cheap sulphuric acid could be produced, an appreciable supply of sulphate of ammonia and superphosphate could be turned out. Attempts are being made to improve the chief crops, and experiments with various rust-resisting Australian wheats show that some of these offer distinct possibilities for Egyptian agriculture, and are worthy of further trial.

The most important crop is cotton, so much so that the tendency is to increase the area devoted to it at the expense of that utilised for food production, and it is now necessary to import a larger proportion of food than in earlier years. The area under cotton increased steadily to a maximum in I9I4 at a greater rate than the total cultivated area, but for the last twenty-three years the average yield per feddan has steadily decreased. This, curiously enough, is attributed chiefly to the improvement in the water-supply. The increased water-supply has not been accompanied by sufficiently increased drainage; the soils become saturated and the subsoil-water remains at a high level-a condition of things that is most unsuitable for the satisfactory growth of the cotton plant. Further, the additional supply of water has rendered possible the extension of cotton-growing to new lands which are less fertile than those which have been longer under cultivation, and the lower yields obtained have reduced the general averages. The varieties grown also influence the yield, as many recently introduced ones, possessing other very desirable qualities, give smaller crops than the older kinds. 